\title{
Dangerous and Adverse Weather Events in Kvemo Kartli (Georgia)
}

\author{
Mariam Elizbarashvili' $^{1}$, Bela Kvirkvelia ${ }^{1}$, Elizbar Elizbarashvili², \\ Shalva Elizbarashvili², Tamar Khuntselia ${ }^{1}$ \\ ${ }^{1}$ Ivane Javakhishvili Tbilisi State University \\ Ilia Tchavtchavadze Avenue 1, \\ Academic Building I, 0179 Tbilisi, Georgia \\ mariam.elizbarashvili@tsu.ge; bela.kvirkvelia@tsu.ge; \\ eelizbar@hotmail.com; shalvaeliz1@gmail.com; takokhuntselia@gmail.com \\ ${ }^{2}$ Institute of Hydrometeorology of Georgian Technical University \\ D.Agmashenebeli Avenue 150a, 0112 Tbilisi, Georgia
}

\section{Extended Abstract}

The current global warming is accompanied by growing damage from hazardous weather and climate events worldwide. It is estimated that about $90 \%$ of the most severe economic losses are caused by hydro meteorological events such as freshets, floods, blizzards, strong winds, heavy rains, hail, fog, droughts, etc. [1]-[3].

Hazardous weather events are the main cause of accidents and disasters related to hydro meteorological factors. In order to elaborate measures for neutralization and mitigation of the effects of hazardous weather phenomena, it is necessary to quantitatively assess the probability of their occurrence and climatic parameters in different geographic conditions. This will make it possible to determine the risk, which quantitatively shows the effect of a hazardous event in a probabilistic form.

The present report illustrates the findings of a study on dangerous and adverse weather events in Kvemo Kartli Region (Georgia). The study region was not selected randomly, as it is directly bordered to the north by the capital of Georgia and supplies the city with agricultural products. The administrative region includes one city of regional subordination (Rustavi) and six municipalities. The population of the region is multinational and accounts for 432,300 people, with the area of 6,528 sq. Km.

The following dangerous and unfavourable weather events typical for the region: fog, hail, high temperatures and drought, as well as heavy rainfall and blizzard, have negative impact on all the sectors of the economy of the region and the whole country, causing substantial material damage.

The article discusses dangerous and adverse weather events creating emergency situations in the region:

- strong wind (When the average wind speed exceeds $15 \mathrm{~m} / \mathrm{s}$, the criterion also includes hurricane wind, when the speed exceeds $32 \mathrm{~m} / \mathrm{s})$;

- fog (All types of fog are considered except for the ground fog, dangerous fogs are discussed separately, when the visibility distance is less than $50 \mathrm{~m}$, the proportion of the days with dangerous fogs is significantly high and accounts for 70 $\%$ of the total number of foggy days) [2];

- heat (When the maximum air temperature exceeds $25^{\circ}$. Among the hot days it is possible to conditionally distinguish the hottest days, when the maximum temperature exceeds $35^{\circ} \mathrm{C}$ );

- hail;

- heavy precipitation (When the amount of rainfall exceeds $30 \mathrm{~mm}$ );

- blizzard (More dangerous - common and low-level blizzards are discussed, excluding ground blizzards).

The materials collected from seven meteorological stations of the region for the period of 1961-2019 were used. A catalogue was compiled and the following characteristics of dangerous weather events were calculated: probability, number of days, frequency, duration, intensity, distribution areas.

There can be distinguished three risk zones by the nature of the intensity and duration of dangerous and adverse weather events in Kvemo Kartli Region: 
1. The most high-risk zones for dangerous and adverse weather events - mountainous regions of Tetri-Tskaro and Dmanisi Municipalities, where strong winds, fog, hail and snowstorms are most likely, long-lasting and intense, as well as their joint occurrence.

2. Medium risk zones for dangerous and adverse weather events - Tsalka Municipality, where the dangerous weather phenomena are somewhat less intense, with the exception of strong winds, which may be of a hurricane character.

3. Lower risk zones for dangerous and adverse weather events- Bolnisi, Marneuli and Gardabani Municipalities, where although all the dangerous weather events are observed, except for a blizzard, strong winds, which in Bolnisi and Gardabani can be of a hurricane character, and hot days are less intense.

The findings of the study can be used for the development of measures to neutralize and mitigate the impact of hazardous weather events.

This work was supported by Shota Rustaveli National Science Foundation of Georgia (SRNSFG) № FR-19-14993.

\section{References}

[1] E. Sh. Elizbarashvili, M. E. Elizbarashvili, Sh. E. Elizbarashvili, M. G. Pipiya, and L. G. Kartvelishvili. "Blizzards in Mountain Regions of Georgia", Russian Meteorology and Hydrology, Vol. 45, No. 1, pp. 58-62. 2020.

[2] E.Sh. Elizbarashvili, M.E. Elizbarashvili, Sh.E. Elizbarashvili. "Investigation of the Frequency of Occurrence of the Most Dangerous Weather Events for Georgia", Russian Meteorology and Hydrology, Vol. 45, No.10, pp. 727-732, 2020.

[3] E.Sh. Elizbarashvili M.E. Elizbarashvili, Sh.E.Elizbarashvili, N.B.Kutaladze, N.M.Gogiya. "Characteristics of Frost Days in the Mountain Regions of Georgia", Russian Meteorology and Hydrology, Vol. 44, No 2, pp. 145-151, 2019. 